\title{
Analysis of potential wake vortex encounters at a major European airport ${ }^{1}$
}

\author{
Frank Holzäpfel \\ Institut für Physik der Atmosphäre, Deutsches Zentrum für Luft- und Raumfahrt, \\ Oberpfaffenhofen, Germany
}

\begin{abstract}
Purpose - Twelve potential wake vortex encounters are investigated that were reported at a major European airport. Almost all encounters occurred in close ground proximity such that most pilots conducted a go-around. The primary purpose of this study is to discriminate between incidents caused by wake vortices or rather by effects like wind shear or turbulence. Detailed knowledge of real world encounter scenarios and the identification of worst case conditions during final approach constitute highly relevant background information to assess the standard scenario used for the definition of revised wake turbulence separations.

Design/methodologylapproach - Wake vortex predictions employing the Probabilistic Two-Phase wake vortex model (P2P) are used to investigate the incidents in detail employing data from flight data recorder, meteorological instrumentation at the airport and numerical weather prediction.

Findings - In the best documented cases the flight tracks through the vortices could be reconstructed in good agreement with wake vortex predictions and recorded aircraft reactions. Five of the eight plausible wake vortex encounters were characterized by weak crosswinds below $1.5 \mathrm{~m} / \mathrm{s}$ combined with tailwinds. This meteorological situation appears favourable for encounters because, on one hand, weak crosswind may compensate the selfinduced lateral propagation of the upwind vortex, such that it may hover over the runway directly in the flight path of the following aircraft. On the other hand, tailwinds limit the propagation of so-called end effects caused by the breakdown of lift during touchdown.

Practical implications - The installation of plate lines beyond the runway tails may improve safety by reducing the number of wake vortex encounters.

Originality/value - The conducted investigations provide high originality and value for both science and operational application.
\end{abstract}

Keywords Wake vortex encounter, Landing, Ground effect, End effects, Wind effects, Plate line

Paper type Research paper

\section{Introduction}

Aircraft trailing vortices, generated as an unavoidable consequence of lift, pose a potential risk to following aircraft. The current separation standards between consecutive aircraft are still being heavily influenced by the early studies carried out in the 1970s, with additional refinements introduced in the 1980s and 1990s (Hallock et al., 1998; Gerz et al., 2002). These aircraft separations limit the capacity of congested airports in a rapidly growing aeronautical environment. The most likely economic scenario for the future European airport demand indicates that there will be around 1.9 million unaccommodated flights in 2035, constituting approximately $12 \%$ of the expected demand (EUROCONTROL, 2013).

In the recent years wake turbulence separations have been readjusted for new aircraft types, new arrival procedures, and modified aircraft weight categories. Whereas an unprecedented test program including many different phases of flight was accomplished for the determination of appropriate separation standards of the A380, most other new developments focused mainly on wake vortex evolution in ground proximity. The rationale for this

\footnotetext{
${ }^{1}$ Aircraft Engineering and Aerospace Technology, Vol. 89, Issue 5, 2017, pp. 634-643, http://dx.doi.org/10.1108/AEAT-01-2017-0043
} 


\section{Frank Holzäpfel}

substantial constraint is that most encounters occur at flight altitudes below $300 \mathrm{ft}$ (Critchley and Foot, 1991; WakeNet3-Europe, 2015). The B747-8 lidar measurement program conducted wake measurements at one wing span above ground, because this altitude was considered the most hazardous scenario (Crouch and Czech, 2012). The lidar measurements employed for the development of the time-based separations procedures at London Heathrow airport also focused on the same flight altitude. The time-based separations concept helps to maintain landing rates in strong headwinds by adjusting aircraft separations according to the current headwind strength (Duffy and Deluca, 2016).

The same flight height restriction applies to the RECAT initiative of ICAO. RECAT phase 1, which is the classification into six categories considering besides the weight the approach speed, wing characteristics and in parts also the rolling moment exerted on following aircraft, has been implemented in November 2012 at Memphis airport (SAFO, 2012), followed by numerous other US airports. The new European separation standard for aircraft wake turbulence called RECAT-EU has been introduced for arrivals and departures at Charles de Gaulle airport Paris in March 2016 (EUROCONTROL 2016). The long-term goal of the RECAT initiative plans for dynamic pairwise separations that consider the aircraft type pairing and the environmental conditions. In SESAR2020 the envisaged developments for static pair wise separations and weather dependent reduced wake turbulence separations both for arrival and departure will likely also focus on wake evolution in the same height range.

The fact that most recent and future wake turbulence separation concepts all focus on wake evolution close to the ground provide good reason to have a closer look at wake vortex behaviour and wake vortex encounters during this phase of flight. Also, for an optimum exploitation of the dynamic pair-wise separations concept, full understanding of wake vortex behaviour during final approach and touchdown is mandatory. Advanced numerical simulations considering the effects of the ground and the touchdown are providing useful insights into the respective wake physics (Stephan et al., 2014). On the other hand, it is necessary to countercheck research results against real world observations. Detailed knowledge of real world encounter scenarios and the identification of worst case conditions during final approach constitute highly relevant background information to assess the standard scenario used for the definition of revised wake turbulence separations.

In this paper potential wake vortex encounters in ground proximity at a major European airport are investigated that were reported in the timeframe of the years 2013 to 2015. Section 2 provides a survey on the investigated incidents whereas section 3 briefly introduces the wake vortex prediction model used for the analysis of the events. Sections 4 to 7 describe four events in detail for which a good data basis of the involved aircraft and the prevailing meteorological conditions was available. Finally, section 8 provides a synopsis of the described cases and eight other cases with an inferior availability of data that are not discussed here in detail.

\section{Survey on Potential Encounters}

Table 1 provides an overview on the investigated incidents. The table covers all potential wake vortex encounters that were reported within a time frame from May 2013 to September 2015 where at least the type of the leading aircraft was known. Listed are month and year, time of day, types of potential vortex generating aircraft and encountering aircraft, temporal or spatial aircraft separation, flight altitude of the encounter, go-around yes or no, pilot perception of what might have caused the incident, prevailing headwind and crosswind strengths as well as the plausibility of an encounter found in these investigations.

The availability of meteorological and aircraft data decreases from the cases listed above to the lower ones. For the cases without knowledge of the encounter altitude an altitude of $12 \mathrm{~m}$ was assumed which corresponds to the average altitude of the documented flight through the vortices and was chosen upon consultation with the local ATC. In cases 5 to 12 the aircraft separation was available only as a difference of minutes. That is the uncertainty of those separation times amounts to $\pm 59 \mathrm{~s}$. 
Analysis of potential wake vortex encounters at a major European airport

Frank Holzäpfel

Table 1 Survey on potential encounters.

\begin{tabular}{|c|c|c|c|c|c|c|c|c|c|}
\hline No. & $\begin{array}{l}\text { Monthl } \\
\text { Year }\end{array}$ & $\begin{array}{l}\text { Time } \\
\text { (UTC) }\end{array}$ & $\begin{array}{c}\text { A/C Type } \\
\text { (lead/follow) }\end{array}$ & Separation & $\begin{array}{c}\text { n Encounter } \\
\text { Altitude }\end{array}$ & Go-around & $\begin{array}{c}\text { Pilot } \\
\text { Perception }\end{array}$ & $\begin{array}{c}\mathrm{HW} / \mathrm{CW} \\
{[\mathrm{m} / \mathrm{s}]}\end{array}$ & $\begin{array}{l}\text { Encounter } \\
\text { Plausibility }\end{array}$ \\
\hline 1 & 09/2015 & $17: 15$ & A320 / A320 & $80 \mathrm{~s}$ & $25-17 m$ & yes & wake turb. & $2.4 /-1.0$ & probable \\
\hline 2 & $08 / 2015$ & $06: 29$ & B737 / A320 & $76 \mathrm{~s}$ & $18 \mathrm{~m}$ & no & wake turb. & $1.5 /-1.2$ & probable \\
\hline 3 & 08/2014 & $17: 14$ & A319 / A320 & $2.4 \mathrm{~nm}$ & $50-30 \mathrm{ft}$ & $\begin{array}{c}\text { only other } \\
\mathrm{a} / \mathrm{c}\end{array}$ & wake turb. & $0.7 /-0.7$ & probable \\
\hline 4 & $05 / 2014$ & $16: 49$ & A321 / A320 & $2.5 \mathrm{~nm}$ & $40 \mathrm{ft}$ & yes & wake turb. & $-0.9 / 1.9$ & probable \\
\hline 5 & 03/2014 & $20: 30$ & A320 / A321 & $1 \mathrm{~min}$ & $12 \mathrm{~m}$ & yes & wake turb. & $-0.5 / 0.2$ & possible \\
\hline 6 & $03 / 2014$ & $18: 43$ & DH8D / A320 & $2 \min$ & $12 \mathrm{~m}$ & yes & wake turb. & $-1.1 / 1.0$ & possible \\
\hline 7 & $11 / 2013$ & $15: 16$ & A340 / F100 & $3 \min$ & $12 \mathrm{~m}$ & yes & wind shear & $-3.1 / 0.5$ & possible \\
\hline 8 & $10 / 2013$ & $16: 40$ & F70 / A321 & $2 \min$ & $12 \mathrm{~m}$ & yes & wind shear & $5.3 /-1.9$ & unlikely \\
\hline 9 & $09 / 2013$ & $21: 45$ & B767 / A320 & $3 \min$ & $12 \mathrm{~m}$ & yes & wind shear & $-3.1 / 0.5$ & possible \\
\hline 10 & $05 / 2013$ & $17: 38$ & A319 / A320 & $2 \min$ & $12 \mathrm{~m}$ & yes & turbulence & $7.9 / 9.4$ & unlikely \\
\hline 11 & $05 / 2013$ & $00: 47$ & A320 / A320 & $3 \mathrm{~min}$ & $1800 \mathrm{ft}$ & yes & turbulence & $5.0 / 3.0$ & unlikely \\
\hline 12 & $05 / 2013$ & $19: 11$ & A321 / A320 & $2 \min$ & $12 \mathrm{~m}$ & yes & wind shear & $6.7 / 3.9$ & unlikely \\
\hline
\end{tabular}

\section{Wake Vortex Parameters and the Wake Vortex Model P2P}

The initial vortex separation, $b_{0}$, amounts to

$$
b_{0}=\frac{\pi}{4} \mathrm{~B}
$$

assuming elliptical circulation distribution, where $B$ is the wing span. The initial circulation of the wake vortices for stationary horizontal flight is calculated according to

$$
\Gamma_{0}=\frac{\mathrm{W}}{\frac{\pi}{4} \rho \mathrm{BV}}
$$

where $\mathrm{W}$ denotes the weight, $\rho$ the air density, and $\mathrm{V}$ the airspeed. The initial vortex descent speed is

$$
w_{0}=\frac{\Gamma_{0}}{2 \pi b_{0}}
$$

For the assessment of the vertical and lateral transport and the decay of the wake vortices the wake vortex prediction model P2P (Probabilistic Two-Phase wake vortex decay and transport model) is employed. The design and applications of the P2P model are described in detail in Holzäpfel (2003), Holzäpfel and Robins (2004), Holzäpfel (2006), Holzäpfel and Steen (2007), and Frech and Holzäpfel (2008). P2P provides probabilistic envelopes for vertical and lateral vortex position as well as circulation of the trailing vortices considering average values and uncertainties of the aircraft parameters weight, wing span, airspeed, height above ground, heading, and flight path angle as well of the environmental parameters wind, turbulence, and thermal stratification.

Vortex behaviour in ground proximity is mainly controlled by the interaction of the vortices with the ground and the crosswind, such that the parameters turbulence and thermal stratification are of minor importance (Holzäpfel and Steen, 2007) and are neglected in this study. To model the vortex divergence in ground proximity image vortices are introduced whereas the subsequent vortex rebound is modelled by the introduction of secondary and tertiary vortices (Holzäpfel and Steen, 2007; Holzäpfel et al., 2016b). For this study the uncertainty allowances of the vortex predictions are adjusted to $95 \%$. For lateral vortex positions also deterministic predictions are displayed in order to demonstrate the average vortex transport. 


\section{Encounter of Wake Vortices Generated by a B737 Aircraft by an A320 Aircraft in August 2015 \\ Description of incident}

In August 2015 an A320 aircraft issued an encounter warning "Roll Attitude High during Landing below $50 \mathrm{ft}$ " eight seconds before touchdown. Below altitudes of $50 \mathrm{ft}$ bank angles beyond $7^{\circ}$ are attributed the severity "Caution". However, only at bank angles of $16^{\circ}$ to $20^{\circ}$ the jet engine or the wing tip of an A320 aircraft might touch the ground. During this incident the bank angle varied between $-8^{\circ}$ and $8^{\circ}$ and achieved a maximum magnitude of $8.2^{\circ}$. These bank angles occurred within a time frame of $5 \mathrm{~s}$ in an altitude range from $60 \mathrm{ft}$ to $10 \mathrm{ft}$. The aircraft encountered the vortex during the initiation of the flare. Presumably the initiation of a go-around could not have avoided touchdown. The pilot counteracted the vortex induced rolling moment efficiently with aileron deflections of up to $-20^{\circ}$. He didn't abort the manually controlled landing and landed safely with bank angles below $2^{\circ}$ and without any unusual vertical acceleration.

The vortex generating aircraft was a B737. The exact instant of time of the touchdown of the leading B737 aircraft is not known. Based on radar images the temporal separation of the aircraft was estimated to $76 \mathrm{~s} \pm 3 \mathrm{~s}$ corresponding to a spatial separation of $3.0 \mathrm{NM} \pm 0.1 \mathrm{NM}$. That is the separation of the aircraft was larger than the radar separation of $2.5 \mathrm{NM}$ prescribed at that airport for aircraft of the weight class MEDIUM.

Figure 1 Sketch of bank angle sequence during flight through right vortex.

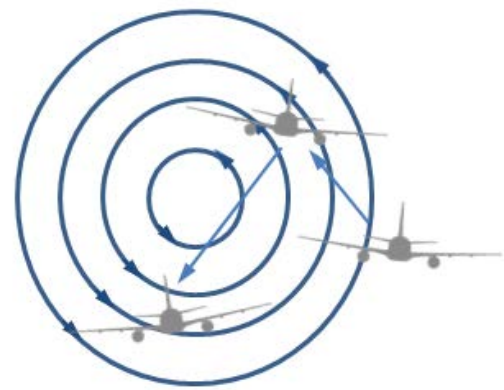

The bank angle sequence of the A320 aircraft (see Figure 1) - first a roll towards the right and then to the left indicates an encounter of the right vortex from the right. Note that in ground proximity the vortices quickly diverge (Holzäpfel and Steen, 2007) such that for this analysis the impact of the left vortex can be neglected. Initially, only the left wing immerses into the upwind zone of the vortex and the aircraft rolls towards the right. Once the aircraft enters deeper into the vortex it follows its rotational direction against clockwise direction; the left wing experiences a downwash and the right wing senses an upwash, hence a rolling moment towards the left. The crosswind component - initially briefly from left (negative), then from right and later again from left - provides further insight with respect to the flight track through the vortex. Accordingly the right vortex has been penetrated from right below, the aircraft then reached the upper right part of the vortex and then flew through it towards left below.

\section{Aircraft parameters and environmental parameters}

Table 2 lists the collected parameters of both involved aircraft. Due to the lack of flight track data of the leading aircraft it is assumed that the leading B737 followed the flight track of the A320 with an uncertainty of \pm 3 m vertically. For the wake vortex predictions it is assumed that the flap tips generating the strongest trailing vortices are situated about $4 \mathrm{~m}$ above ground. The parameters employed for the wake vortex predictions are listed in Table 2 in bold face together with the employed uncertainties. In the lowest three lines Table 2 specifies the initial wake vortex parameters vortex spacing, circulation, and descent speed derived from the parameters above. The respective uncertainties are derived by the $\mathrm{P} 2 \mathrm{P}$ model from the uncertainties of the above listed aircraft parameters and are not specified here. 
Table 2 Aircraft parameters; data used for P2P predictions in bold face.

\begin{tabular}{|c|c|c|}
\hline & Leader & Follower \\
\hline Aircraft Type & B737 & A320 \\
\hline Length & $33.60 \mathrm{~m}$ & $37.57 \mathrm{~m}$ \\
\hline Wing Span & $35.8 \mathrm{~m}$ & $34.1 \mathrm{~m}$ \\
\hline Maximum Landing Weight & $58,604 \mathrm{~kg}$ & $64,500 \mathrm{~kg}$ \\
\hline Landing Weight & $55,446 \mathrm{~kg} \pm 50 \mathrm{~kg}$ & $61,100 \mathrm{~kg}$ \\
\hline Average Velocity During Event & 138 knots \pm 4 knots & 132 knots \pm 3.3 knots \\
\hline Touchdown Time & $06: 28: 20 \pm 3 s$ & $06: 29: 36 \pm 1 \mathrm{~s}$ \\
\hline Beginning of Event & - & $06: 29: 28 \pm 1 \mathrm{~s}$ \\
\hline Height (AGL) at Beginning of Event & $18 \mathrm{~m} \pm 3 \mathrm{~m}$ & $60 \mathrm{ft}(18.3 \mathrm{~m})$ \\
\hline Height (AGL) at End of Event & - & $6.0 \mathrm{ft}(1.8 \mathrm{~m})$ \\
\hline Heading & $344^{\circ} \pm 2^{\circ}$ & $344^{\circ}$ \\
\hline Flightpath Angle & $3^{\circ} \pm 0.5^{\circ}$ & $-2.8^{\circ}$ \\
\hline Bank Angle & $0^{\circ} \pm 0.5^{\circ}$ & - \\
\hline Vortex Spacing & $28.1 \mathrm{~m}$ & - \\
\hline Initial Circulation & $229 \mathrm{~m}^{2} / \mathrm{s}$ & - \\
\hline Initial Descent Speed & $1.3 \mathrm{~m} / \mathrm{s}$ & - \\
\hline
\end{tabular}

The transport and decay of the vortices is mainly controlled by the prevailing environmental conditions, where the wind has the dominant impact on vortex transport. Table 3 lists the meteorological conditions available from different data sources within the relevant height range of the potential encounter. Figures 2 and 3 depict the vertical profiles of headwind and crosswind, respectively, within a larger height range. Besides the analysis data of the weather prediction model COSMO-DE and the weather prediction data of the ECMWF model there are aircraft measurements of the encountering aircraft as well as of different in-situ and remote sensing instrumentation. A wind profiler is situated about $2 \mathrm{~km}$ north of the runway threshold and a SODAR about $5 \mathrm{~km}$ northwest form the threshold. The anemometer 34 is located next to the touchdown zone, another anemometer at the outer marker about $4 \mathrm{NM}$ from the threshold. The aircraft wind measurements were averaged along a height range of $20 \mathrm{~m}$ to $50 \mathrm{~m}$, because the measurements during the encounter at heights below $20 \mathrm{~m}$ consist of a superposition of ambient wind and wake vortex velocities. The standard deviations within this height range are given in parenthesis. 


\section{Frank Holzäpfel}

Table 3 Meteorological parameters, standard deviations of aircraft measurements in parenthesis, averages without COSMO and ECMWF data in square brackets.

\begin{tabular}{ccccccc}
\hline \hline Data Source & $\begin{array}{c}\text { Temperature } \\
{\left[{ }^{\circ} \mathrm{C}\right]}\end{array}$ & $\begin{array}{c}\text { Density } \\
{\left[\frac{\mathrm{kg}}{\mathrm{m}^{3}}\right]}\end{array}$ & $\begin{array}{c}\text { Wind Dir } \\
{\left[{ }^{\circ}\right]}\end{array}$ & $\begin{array}{c}\text { Wind Speed } \\
{\left[\frac{\mathrm{m}}{\mathrm{s}}\right]}\end{array}$ & $\begin{array}{c}\text { Headwind } \\
{\left[\frac{\mathrm{m}}{\mathrm{s}}\right]}\end{array}$ & \multicolumn{2}{c}{ Crosswind $^{2}$} \\
\hline A320 & 19 & - & $354.5(4.2)$ & $2.1(0.6)$ & $2.1(0.6)$ & $-0.3(0.25)$ \\
\hline $\begin{array}{c}\text { METAR } \\
\text { COSMO-DE 06 } \\
\text { UTC }\end{array}$ & 18 & 1.21 & 20 & 2.0 & 1.6 & -1.2 \\
\hline $\begin{array}{c}\text { COSMO-DE 07 } \\
\text { UTC }\end{array}$ & 19.5 & - & 101.3 & 3.2 & -1.5 & -2.8 \\
\hline $\begin{array}{c}\text { ECMWF 06 UTC } \\
\text { ECMWF 07 UTC }\end{array}$ & 18.3 & - & 93.4 & 3.4 & -1.1 & -3.2 \\
\hline $\begin{array}{c}\text { Anemometer } \\
\text { (WMA) 34 }\end{array}$ & - & - & 122 & 3.6 & -2.7 & -2.5 \\
\hline Outer Marker 34 & 18.3 & - & 128 & 3.4 & -2.7 & -2.0 \\
\hline SODAR & - & - & 6.6 & 2.6 & 2.4 & -1.0 \\
\hline Wind Profiler & - & - & 27.8 & 1.6 & 1.2 & -1.1 \\
\hline Average & 18.8 & - & 55 & 2.1 & 0.7 & -1.9 \\
\hline STDEV & 0.72 & - & $45[22]$ & $0.69[0.34]$ & $1.8[0.64]$ & $0.83[0.52]$ \\
\hline \hline
\end{tabular}

The wind data mainly exhibit a north-easterly wind direction, where the anemometer 34 and the aircraft data display a northerly wind direction and the weather prediction data an easterly flow. The arithmetic mean direction features with $45^{\circ}$ wind from northeast with a standard deviation of $45^{\circ}$. For calculating the averages and standard deviations (STDEV) of the data from all sources in tables 3 and 7, average values of the numerical weather prediction data between 6 and 7 UTC are used. Excluding the strongly deviating COSMO-DE and ECMWF wind directions, the average wind direction amounts to $23^{\circ}$ with a standard deviation reduced to $22^{\circ}$ (values in square brackets). All data sources feature a weak crosswind from the right in the coordinate system of the aircraft on the order of magnitude of the initial descent speed of the wake vortices generated by the B737 (see Table 2). The measurement data display consistently a weak headwind, whereas the weather predictions show a weak tailwind. The different head- and tailwinds are also on the order of the initial vortex descent speed.

Figures 2 and 3 show the vertical profiles of headwind and crosswind of the different data sources. For the headwind two groups can be identified: the weather prediction data featuring tailwinds slightly increasing with height and the measurement data with almost height independent weak headwinds. All crosswinds are negative (from right to left) where similar groupings can be identified: model data with stronger winds increasing with height and measurement data with weaker and almost constant profiles.

\footnotetext{
${ }^{2}$ Positive crosswind corresponds to wind from left to right in the coordinate system of the aircraft.
} 


\section{Frank Holzäpfel}

Figure 2 Vertical profiles of headwind of the different data sources.

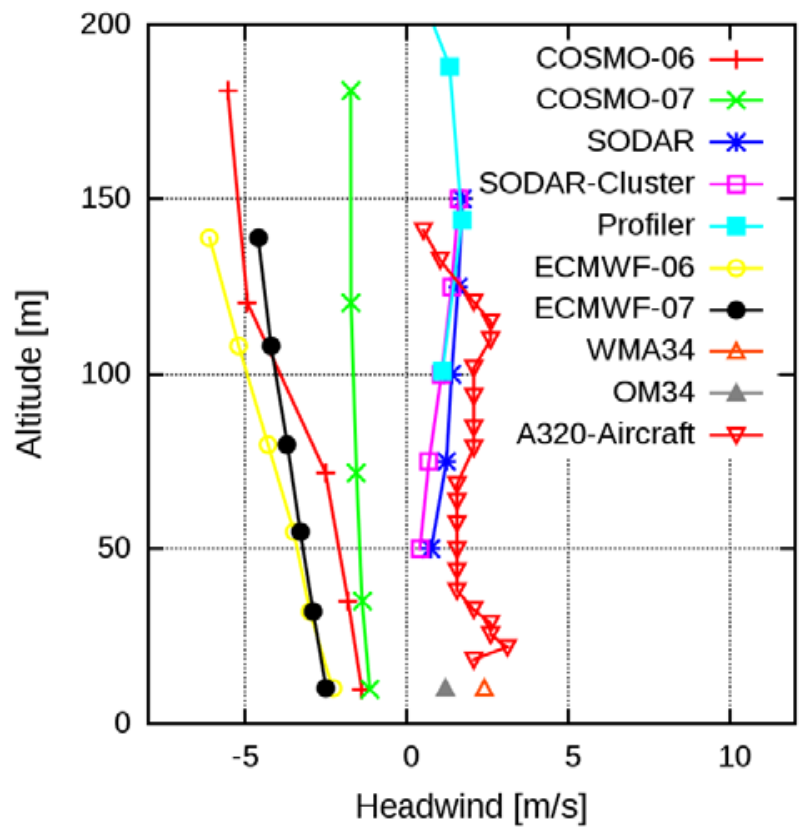

Figure 3 Vertical profiles of crosswind of the different data sources.

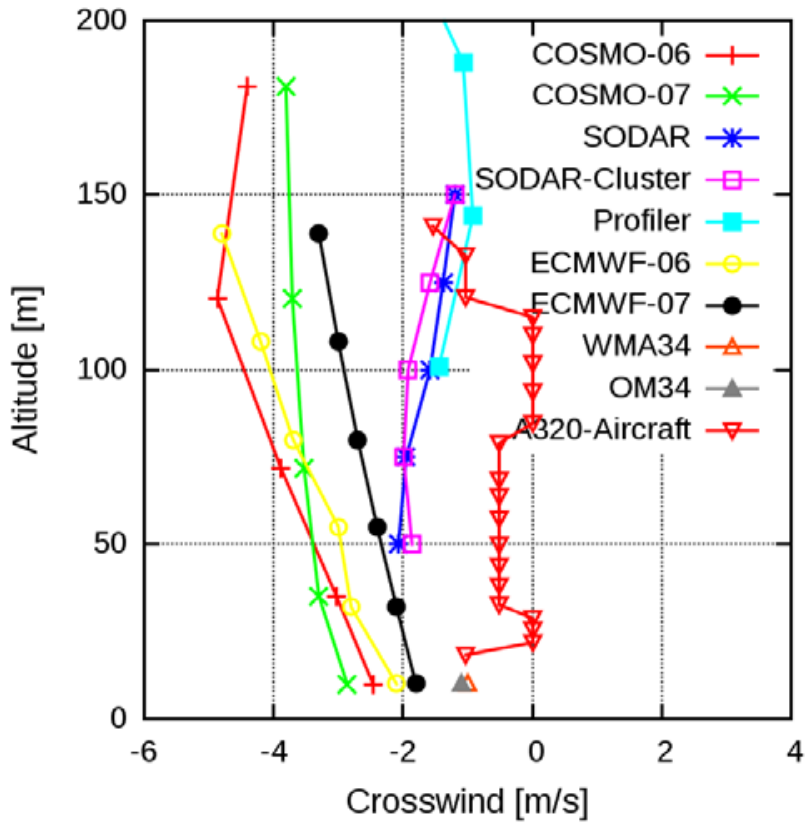




\section{Wake vortex predictions}

The predictions of wake vortex behaviour with the P2P model employ the aircraft parameters in Table 2 in combination with three different sets of meteorological parameters in Table 3: (1) measurements of the A320 with the respective standard deviations, (2) average values of all available meteorological data including the respective standard deviations as well as (3) average values of all meteorological data without the model data including the standard deviations.

Figure 4 displays the P2P predictions for case (1). The probabilistic envelopes correspond to a probability of $95 \%$. The vortex age as well as its height at the beginning of the encounter are denoted by black lines. Both, wake vortex transport and strength indicate that the incident may be very well considered a wake vortex encounter. At a vortex age of $76 \mathrm{~s}$ the circulation resides between $40 \mathrm{~m}^{2} / \mathrm{s}$ and $123 \mathrm{~m}^{2} / \mathrm{s}$, corresponding to values where distinct aircraft reactions may be expected for an encountering A320. The encounter height lies about midway between the probabilistic envelopes. For the lateral position the probabilistic envelopes are complemented by deterministic predictions with varying initial conditions and model parameters (cluster of lines with different colours). It appears plausible that the starboard vortex was encountered from right in agreement with the analysis of aircraft reaction and crosswind (see Description of incident).

Figure 4 center illustrates that the vortices have been transported by the headwind against flight direction by about $160 \mathrm{~m}$ ( $\mathrm{x}$-value denoted by magenta line). This allows a more precise estimate of the altitude where the vortices were generated of $11 \mathrm{~m} \pm 1 \mathrm{~m}$. The corresponding wake vortex predictions are displayed in Figure 5 . As a consequence of the more intense interaction with the ground the vortices are already weaker but with up to 93 $\mathrm{m}^{2} / \mathrm{s}$ still sufficiently strong. Now it appears also plausible that the starboard vortex is penetrated from right below, as suggested by the initial analysis of the incident.

Figure 6 employs the average values of all wind data in Table 3. Obviously the spread of the wind data with a standard deviation of $45^{\circ}$ is so substantial that the transport of the vortices by the crosswind becomes very uncertain. As a result the wake vortex predictions become very unspecific and could not be used to derive reasonable conclusions.

Using average values and standard deviations of all wind measurement data (without model data), the uncertainties of the crosswind transport are substantially reduced (see Figure 7). In particular the deterministic transport of the starboard vortex supports the thesis that it was penetrated from right.

Figure 4 Wake vortex predictions employing aircraft parameters in Table 2 and A320 measurements in Table 3.
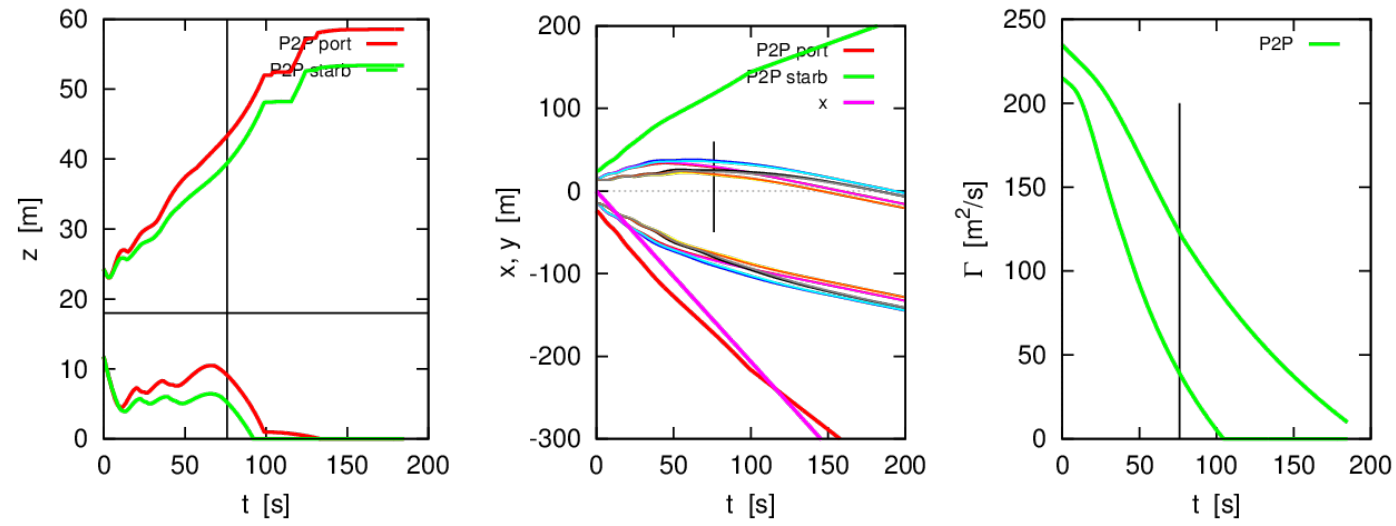


\section{Frank Holzäpfel}

Figure 5 Wake vortex predictions employing aircraft parameters in Table 2 and A320 measurements in Table 3 with refined estimate of vortex generation altitude of $11 \mathrm{~m}$.
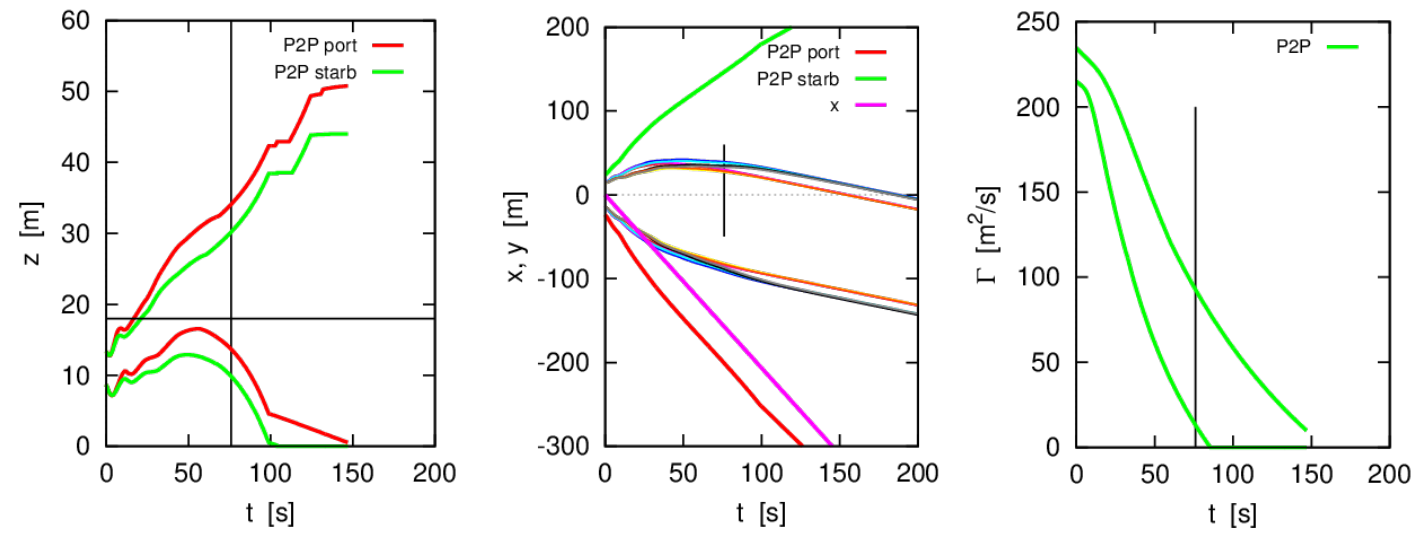

Figure 6 Wake vortex predictions employing aircraft parameters in Table 2 and average values of all meteorological data in Table 3.
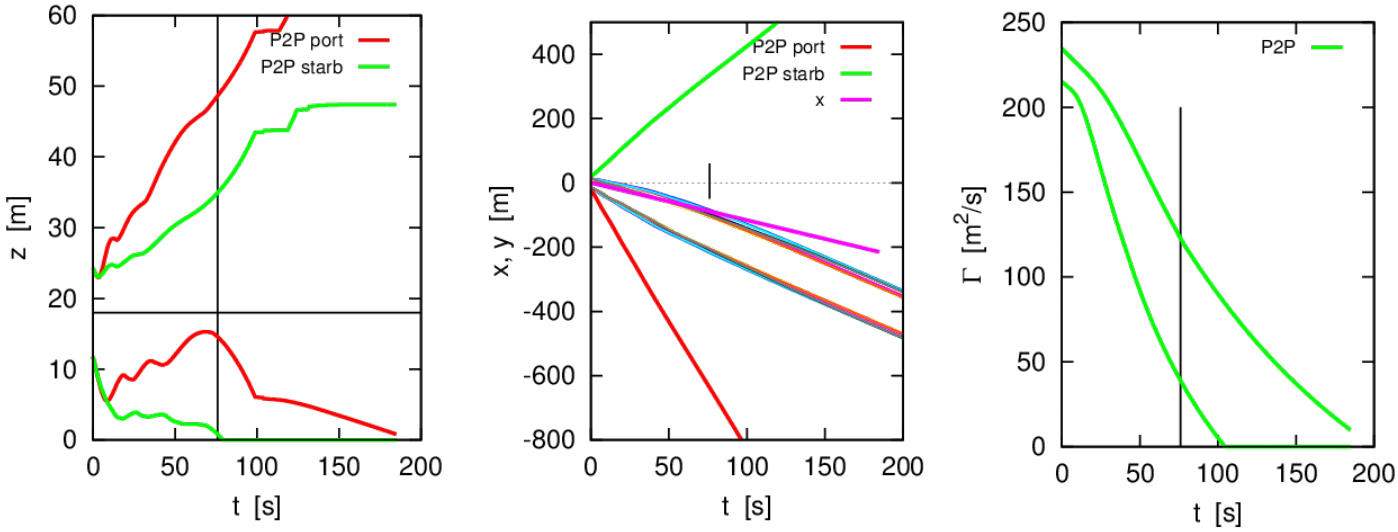

Figure 7 Wake vortex predictions employing aircraft parameters in Table 2 and average values of all meteorological measurements in Table 3.
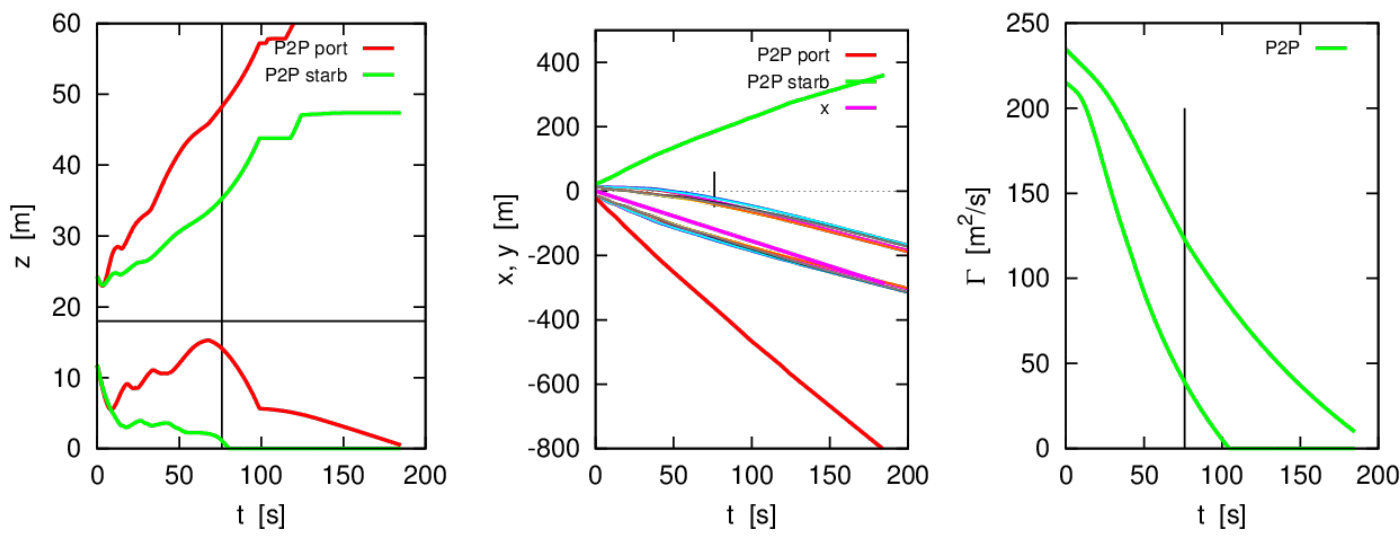


\section{Encounter of Wake Vortices Generated by an A320 Aircraft by another A320 in September 2015 \\ Description of incident}

In September 2015 an A320 aircraft experienced bank angles of up to $-5.8^{\circ}$ directly prior to touchdown at 17:14:45 UTC. The maximum positive bank angle amounted to $4.4^{\circ}$. The increased bank angles occurred in a height range from $17 \mathrm{~m}$ to $4.5 \mathrm{~m}$ above ground. The pilot decided to conduct a go-around and counteracted the rolling moment with aileron deflections of up to $10^{\circ}$. The suspected encounter lasted about $4 \mathrm{~s}$ to $6 \mathrm{~s}$.

The bank angle sequence, first rolling towards the left and then to the right, would indicate an encounter of the left vortex from the left side. However, the first rolling towards the right was presumably almost completely compensated by the pilot's aileron deflection of up to $-6.7^{\circ}$. Afterwards aileron deflections of up to $9.8^{\circ}$ and $-8.9^{\circ}$ were recorded. So the incident was presumably rather an encounter of the right vortex connected with a bank angle sequence right, left, right, similar to the incident investigated in the previous section (see Figure 8). The crosswind remains negative throughout the encounter indicating the vortex was crossed above its centre. If the encounter duration was not deduced from the bank angle of the A320 but from the compensating aileron deflections, the encounter would have started already $2 \mathrm{~s}$ earlier at an altitude of $25 \mathrm{~m}$. The leading aircraft, also an A320, had passed the encounter position about $80 \mathrm{~s}$ earlier. The minimum separation between the aircraft was $3.1 \mathrm{NM}$.

Figure 8 Sketch of bank angle sequence during flight through right vortex.

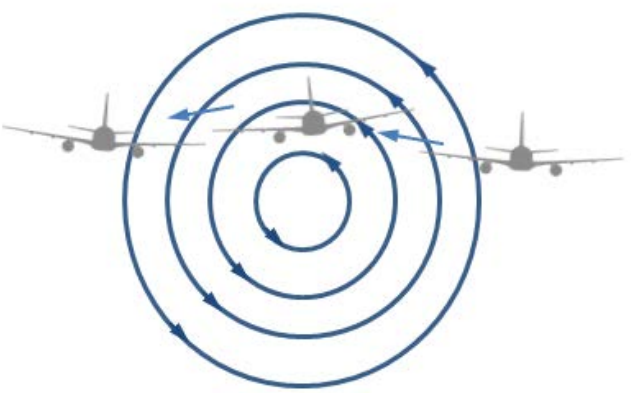

\section{Aircraft parameters and environmental parameters}

The aircraft parameters of both aircraft listed in Table 4 are taken from the respective flight data recorder data. The parameters employed for the wake vortex predictions are listed in in bold face together with the employed uncertainties. The lowest three lines specify the initial wake vortex parameters vortex spacing, circulation, and descent speed derived from the parameters above.

Table 4 Aircraft parameters; data used for P2P predictions in bold face.

\begin{tabular}{|c|c|c|}
\hline & Leader & Follower \\
\hline Aircraft Type & A320 & A320 \\
\hline Wing Span & $34.1 \mathrm{~m}$ & $34.1 \mathrm{~m}$ \\
\hline Landing Weight & $60,100 \mathrm{~kg}$ & $57,700 \mathrm{~kg}$ \\
\hline Average Velocity & $72.0 \mathrm{~m} / \mathrm{s} \pm 1.3 \mathrm{~m} / \mathrm{s}$ & $72 \mathrm{~m} / \mathrm{s}$ \\
\hline Touchdown Time & $17: 13: 34$ & go-around \\
\hline Beginning of Event & - & $17: 14: 43$ \\
\hline Height (AGL) at Beginning of Event & $25 \mathrm{~m}(17 \mathrm{~m}) \pm 1 \mathrm{~m}$ & $25 \mathrm{~m}(17 \mathrm{~m})$ \\
\hline Height (AGL) at End of Event & & $4 \mathrm{~m}$ \\
\hline
\end{tabular}




\begin{tabular}{ccl}
\hline Vortex Spacing & $26.8 \mathrm{~m}$ & - \\
\hline Initial Circulation & $255 \mathrm{~m}^{2} / \mathrm{s}$ & - \\
\hline Initial Descent Speed & $1.5 \mathrm{~m} / \mathrm{s}$ & - \\
\hline \hline
\end{tabular}

The wind measurements of the following aircraft in Table 5 were averaged over a height range of $22 \mathrm{~m}$ to $50 \mathrm{~m}$ above ground, because the wind data recorded during the encounter are adulterated by the wake vortex wind speeds. In the table the respective standard deviations within the corresponding height ranges are given in parenthesis.

The aircraft measurements of the vortex generator were averaged across the height range below $24 \mathrm{~m}$, where the encounter actually occurred. Within that small height range wind direction changes of over $100^{\circ}$ are observed which raises the question whether the wind measurements of the leading aircraft were also disturbed by a wake vortex. For this reason additionally winds are averaged across the height range from $25 \mathrm{~m}$ to $51 \mathrm{~m}$. The wind measurements of both aircraft deviate substantially in wind direction and speed.

Table 5 Meteorological parameters, standard deviations in parenthesis.

\begin{tabular}{ccccc}
\hline Data Source & Wind Dir $\left[^{\circ}\right]$ & Wind Speed $\left[\frac{\mathrm{m}}{\mathrm{s}}\right]$ & Headwind $\left[\frac{\mathrm{m}}{\mathrm{s}}\right]$ & Crosswind $\left[\frac{\mathrm{m}}{\mathrm{s}}\right]$ \\
\hline A320 (follower) & $81.6(8.6)$ & $1.2(0.55)$ & $-0.2(0.2)$ & $-1.2(0.27)$ \\
\hline A320 (leader) & $137.5(32)^{3}$ & $3.3(0.7)$ & $-2.7(1.3)$ & $-0.9(1.0)$ \\
& $135.8(1.8)^{4}$ & $3.4(0.1)$ & $-3,0(0.2)$ & $-1.6(0.04)$ \\
\hline \hline
\end{tabular}

\section{Wake vortex predictions}

The wake vortex predictions with the $\mathrm{P} 2 \mathrm{P}$ model employ the aircraft parameters given in Table 4 and the wind data of Table 5. Figure 9 depicts the P2P predictions using the wind data of the encountering aircraft and a flight altitude of $17 \mathrm{~m} \pm 1 \mathrm{~m}$. The starboard vortex resides at the time of the encounter (vortex age $80 \mathrm{~s}$ ) exactly in the middle of the predicted $95 \%$ height range of the starboard vortex. The lateral vortex position of the deterministic prediction is displaced only by $35 \mathrm{~m}$ from the vortex core and quite centrally located in the $95 \%$ envelopes. The predicted vortex circulation below $100 \mathrm{~m}^{2} / \mathrm{s}$ explains the minor rolling moments experienced by the A320. All in all it appears very plausible that the right vortex was encountered from the right. A vortex generation height of $25 \mathrm{~m}$ (not shown) yields quite similar vortex behaviour characteristics and the vortex encounter appears as plausible as with the lower vortex generation height.

Figure 10 displays the vortex predictions for the wind measurements of the leading aircraft in a height range of $25 \mathrm{~m}$ to $51 \mathrm{~m}$ in Table 5. Here the vortex transport by the tailwind of $3 \mathrm{~m} / \mathrm{s}$ is considered such that the vortex generation altitude was adjusted to $30 \mathrm{~m}$. The vortex predictions employing the wind measurements below $24 \mathrm{~m}$ are not shown, because the average wind is almost identical as in Figure 10 but the respective uncertainties are that massive that any encounter situation would appear plausible.

Both the vertical vortex position as well as its strength at $80 \mathrm{~s}$ make an encounter likely. Because of the minor variability of the crosswind data the A320 resides outside of the $95 \%$ envelopes of the lateral vortex position, but still not too far from the deterministic predictions. Employing the wind data of the leading aircraft on lower altitude, however, the A320 position is found far inside the predicted probabilistic lateral boundaries (not shown). Increasing the vortex generation height by $8 \mathrm{~m}$ again leads to minor changes; the encounter appears as probable as for the lower generation height (not shown). In summary, a wake vortex encounter appears probable for all investigated combinations of wind data and flight altitudes. Further, the synopsis of wake vortex predictions, aircraft reactions, pilot inputs, and wind data enable a consistent reconstruction of the flight track through the vortices.

\footnotetext{
${ }^{3}$ below $24 \mathrm{~m}$

${ }^{4}$ in the height range from $25 \mathrm{~m}$ to $51 \mathrm{~m}$
} 


\section{Frank Holzäpfel}

Figure 9 Wake vortex predictions employing aircraft parameters in Table 4 and the wind data of the following aircraft in Table 5.
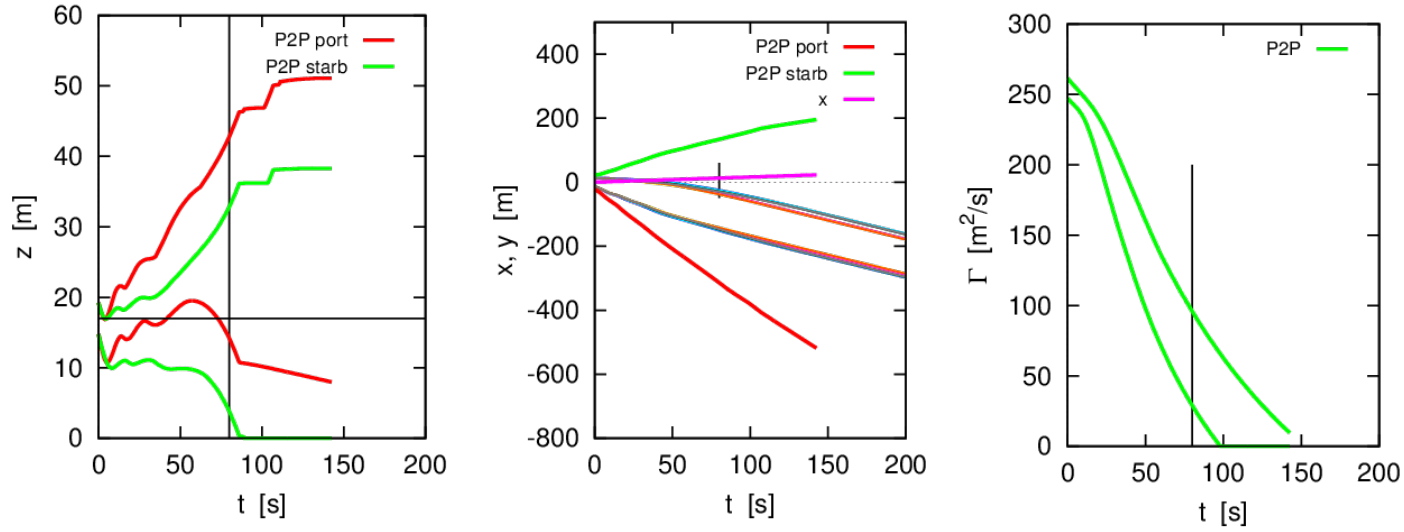

Figure 10 Wake vortex predictions employing aircraft parameters in Table 4 and the wind data of the leading aircraft within the height range $25 \mathrm{~m}$ to $51 \mathrm{~m}$ in Table 5.
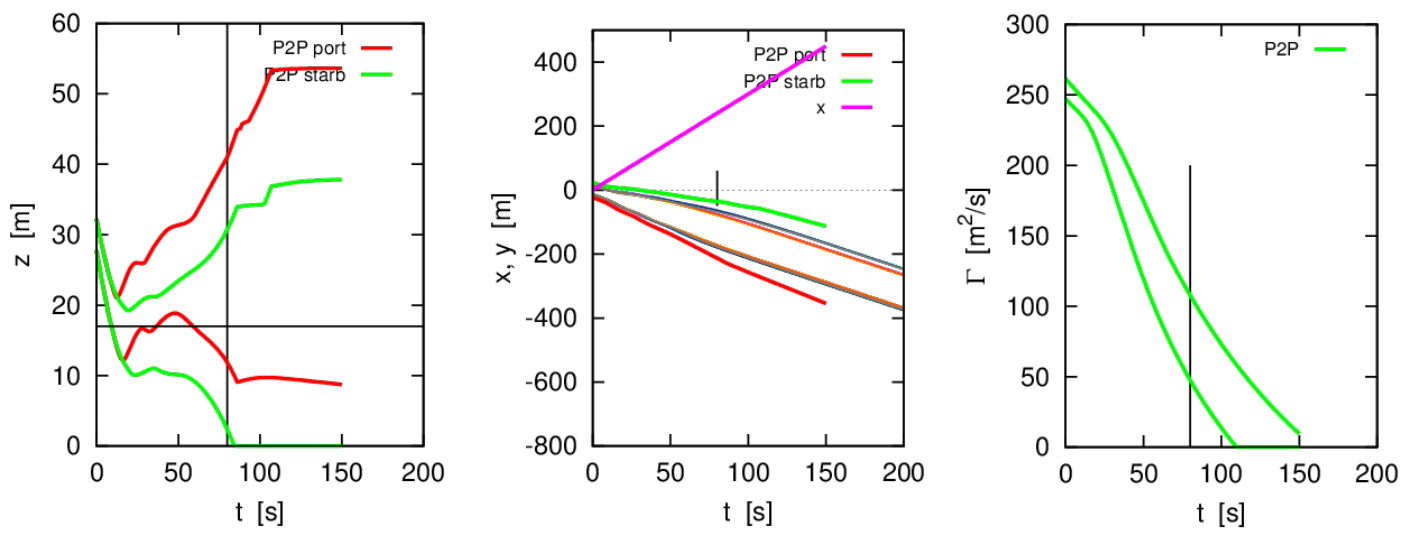

\section{Encounter of an A320 Aircraft behind an A319 in August 2014}

\section{Description of incident}

The pilot report of a presumed encounter of an A320 aircraft in August 2014 stated: “... had during flare between about $50-30 \mathrm{ft}$ a roll input towards the right, in my opinion triggered by wake turbulence - wind calm - separation $2.4 \mathrm{NM}$, according our TCAS preceding A319 ... we didn't initiate a go-around, because my co-pilot corrected very smoothly, such that we landed on the centreline just a little longer - but it was always safe according to my and her opinion." The aircraft separation of 2.4 NM corresponds to $62 \mathrm{~s}$. Several preceding aircraft reported wake turbulence with roll input on short final.

\section{Aircraft parameters and environmental parameters}

Table 6 lists the known and the researched aircraft parameters. The flight speed was taken from the BADA (2013) data base. Measurements of the landing weight at the airports Memphis und Dallas Fort Worth indicate that the average landing weight amounts to $85 \%$ of the maximum landing weight, MLW (Delisi et al. 2013). Other sources confirm this result (EUROCONTROL and FAA, 2011). Accordingly, the landing weight was adjusted to $85 \%$ of the maximum landing weight with an uncertainty of $\pm 7 \%$. Table 7 lists the collected wind data of the different sources including weather prediction model data and in-situ and remote sensing data at the airport. Aircraft wind measurements are not available. 
Analysis of potential wake vortex encounters at a major European airport

\section{Frank Holzäpfel}

Table 6 Aircraft parameters; data used for P2P predictions in bold face.

\begin{tabular}{|c|c|c|}
\hline & Leader & Follower \\
\hline Aircraft Type & A319 & A320 \\
\hline Wing Span & $34.1 \mathrm{~m}$ & $34.1 \mathrm{~m}$ \\
\hline Maximum Landing Weight & $61,000 \mathrm{~kg}$ & $64,500 \mathrm{~kg}$ \\
\hline Landing Weight & $51,850 \mathrm{~kg} \pm 4270 \mathrm{~kg}$ & $54,825 \mathrm{~kg} \pm 4500 \mathrm{~kg}$ \\
\hline Estimated Velocity & $65 \frac{m}{s} \pm 3 \frac{m}{s}$ & $70 \frac{\mathrm{m}}{\mathrm{s}} \pm 3 \frac{\mathrm{m}}{\mathrm{s}}$ \\
\hline Beginning of Event & - & $17: 14$ \\
\hline Height (AGL) & $40 \mathrm{ft} \pm 5 \mathrm{ft}$ & $50-30 \mathrm{ft}$ \\
\hline Vortex Spacing & $26.8 \mathrm{~m}$ & - \\
\hline Initial Circulation & $245 \mathrm{~m}^{2} / \mathrm{s}$ & - \\
\hline Initial Descent Speed & $1.5 \mathrm{~s}$ & - \\
\hline
\end{tabular}

Table 7 Meteorological parameters.

\begin{tabular}{ccccc}
\hline \hline Data source & Wind Dir $\left[{ }^{\circ}\right]$ & Wind Speed $\left[\frac{\mathrm{m}}{\mathrm{s}}\right]$ & Headwind $\left[\frac{\mathrm{m}}{\mathrm{s}}\right]$ & Crosswind $\left[\frac{\mathrm{m}}{\mathrm{s}}\right]$ \\
\hline \hline COSMO-DE 17 UTC & 303 & 1.8 & - & - \\
\hline COSMO-DE 18 UTC & 303 & 2.3 & - & - \\
\hline ECMWF 17 UTC & 340 & 2.6 & - & - \\
\hline ECMWF 18 UTC & 331 & 2.6 & 0.7 & -0.7 \\
\hline Anemometer 34 & 30 & 1.0 & 2.1 & -0.9 \\
\hline SODAR & 8 & 2.3 & 2.1 & -0.4 \\
\hline SODAR Cluster & 354 & 2.1 & - & - \\
\hline Wind Profiler & 3 & 2.9 & 2.2 & 0.31 \\
\hline Average & 336 & 2.2 & - & - \\
\hline STDEV & 29 & 0.62 &
\end{tabular}

\section{Wake vortex predictions}

Figure 11 illustrates the wake vortex predictions based on the aircraft parameters in Table 6 and the average wind data with the respective standard deviations in Table 7 . The computations already consider the headwind transport by reducing the vortex generation height by $7 \mathrm{~m}$. With this measure the encounter altitude is centred within the probabilistic envelopes. Without this height correction the encounter height falls onto the lower bound of the likely vortex altitude at $62 \mathrm{~s}$ (not shown). On the other hand, the uncertainty of the crosswind is that large that no reasonable conclusion can be drawn from the lateral vortex transport. The average crosswind would indicate an encounter of the port vortex. The circulation values appear consistent with a sensible encounter that can be well balanced by a pilot.

Figure 12 shows the P2P predictions employing the aircraft parameters in Table 6 and the anemometer data in Table 7. If no aircraft data is available the anemometer data should represent the actual wind situation the best, because the data is acquired temporally and spatially the closest to the location of the encounter. In the plots the flight altitude of the generator aircraft has been reduced by $2 \mathrm{~m}$ in order to consider the transport of the vortices by the headwind. 


\section{Frank Holzäpfel}

Now it is the starboard vortex that is directly located within the flight track of the A320, both with respect to its vertical and its lateral position. The roll input towards the right reported by the pilot agrees well with the encounter of the starboard vortex from the right where the left wing penetrates the upwind region of the vortex. So the P2P predictions based on the anemometer data make an encounter of the A320 into the wake vortices of the leading A319 very plausible.

Figure 11 Wake vortex predictions employing aircraft parameters in Table 6 and the wind data in Table 7.
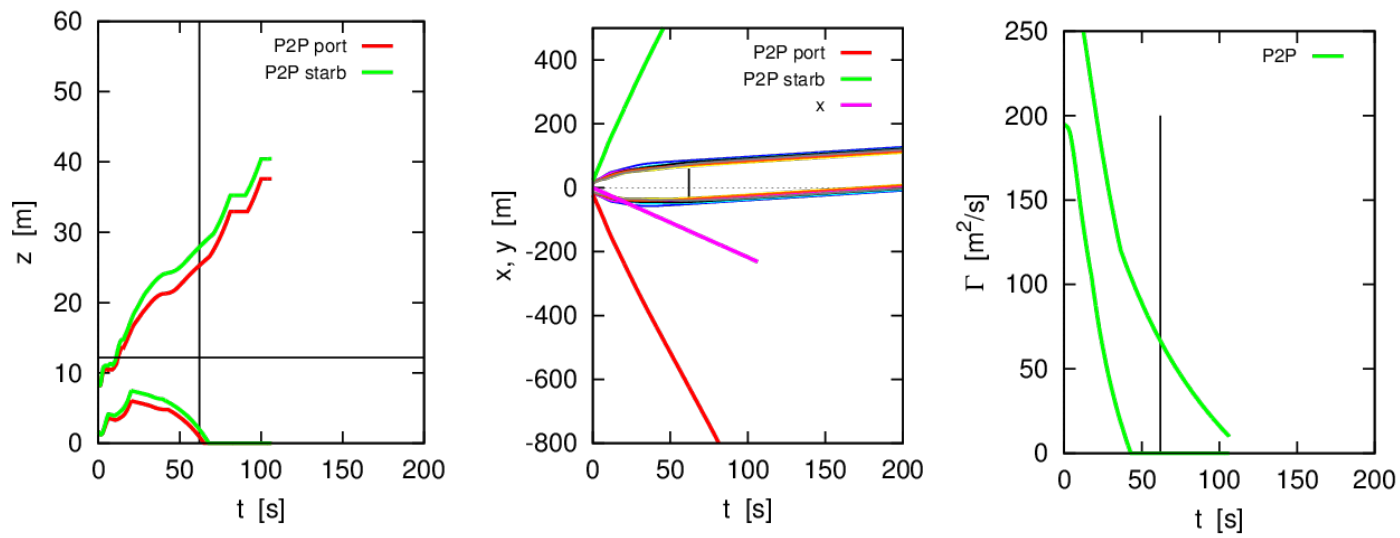

Figure 12 Wake vortex predictions employing aircraft parameters in Table 6 and anemometer data in Table 7.
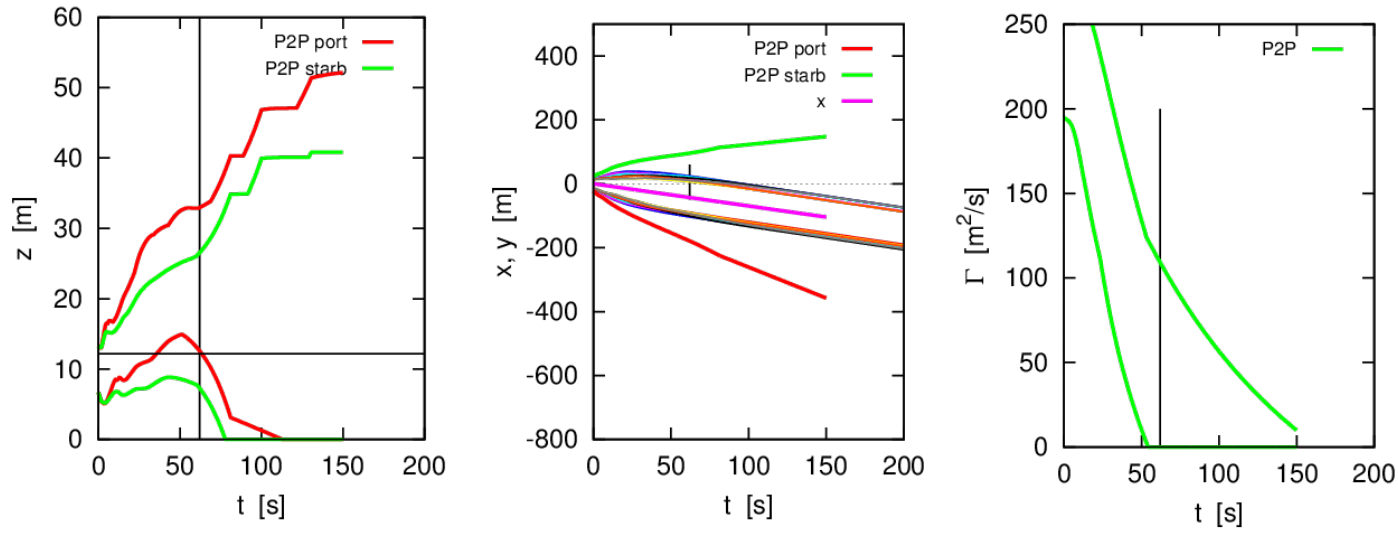

\section{Encounter of an A320 Aircraft behind an A321 in May 2014 \\ Description of incident}

During May 2014 an aircraft of type A320 experienced a presumed encounter during final approach. The distance to the leading A321 aircraft was $2.5 \mathrm{NM}$. The pilot report stated: "After turbulence encountering during flare (around $40 \mathrm{ft}$ ) performed go around. 2nd approach and landing uneventful."

\section{Aircraft parameters and environmental parameters}

Table 8 lists the available and the researched aircraft parameters. As in the previous section flight speeds are retrieved from the BADA (2013) data base and the landing weights are adjusted to $85 \%$ of the maximum landing weight. The meteorological parameters are found in Table 9. 
Analysis of potential wake vortex encounters at a major European airport

\section{Frank Holzäpfel}

Table 8 Aircraft parameters; data used for P2P predictions in bold face.

\begin{tabular}{ccc}
\hline & Leader & Follower \\
\hline \hline Aircraft Type & A321 & A320 \\
\hline Wing Span & $\mathbf{3 4 . 1} \mathbf{~ m}$ & $34.1 \mathrm{~m}$ \\
\hline Maximum Landing Weight & $75,500 \mathrm{~kg}$ & $64,500 \mathrm{~kg}$ \\
\hline Landing Weight & $\mathbf{6 4 , 1 7 5} \mathbf{~ k g} \pm \mathbf{5 2 8 5} \mathbf{~ k g}$ & $54,800 \mathrm{~kg} \pm 4515 \mathrm{~kg}$ \\
\hline Estimated Velocity at Event & $\mathbf{7 1} \frac{\mathbf{m}}{\mathbf{s}} \pm \mathbf{3} \frac{\mathbf{m}}{\mathbf{s}}$ & $70 \frac{\mathrm{m}}{\mathrm{s}} \pm 3 \frac{\mathrm{m}}{\mathrm{s}}$ \\
\hline Beginning of Event & - & $16: 49$ \\
\hline Height (AGL) at Event & $\mathbf{5 3} \mathbf{f t} / \mathbf{5 0} \mathbf{f t}$ & $40 \mathrm{ft}$ \\
\hline Vortex Spacing & $26.8 \mathrm{~m}$ & - \\
\hline Initial Circulation & $281 \mathrm{~m} / \mathrm{s}$ & - \\
\hline Initial Descent Speed & $1.7 \mathrm{~m} / \mathrm{s}$ & - \\
\hline \hline
\end{tabular}

Table 9 Meteorological parameters.

\begin{tabular}{ccccc}
\hline \hline Data Source & Wind Dir $\left[^{\circ}\right]$ & Wind Speed $\left[\frac{\mathrm{m}}{\mathrm{s}}\right]$ & Headwind $\left[\frac{\mathrm{m}}{\mathrm{s}}\right]$ & Crosswind $\left[\frac{\mathrm{m}}{\mathrm{s}}\right]$ \\
\hline \hline METAR & 300 & 8.7 & - & - \\
\hline COSMO-DE 16 UTC & 197 & 4.2 & - & - \\
\hline COSMO-DE 17 UTC & 193 & 2.3 & - & - \\
\hline ECMWF 16 UTC & 309 & 2.4 & - & - \\
\hline ECMWF 17 UTC & 191 & 1.8 & - & - \\
\hline Anemometer 34 & $230 \pm 5$ & $2.1 \pm 0.2$ & -0.9 & - \\
\hline SODAR & 225 & 3.5 & - & - \\
\hline SODAR Cluster & 223 & 3.5 & - & - \\
\hline Wind Profiler & 232 & 3.9 & - & - \\
\hline Average & 234 & 3.6 & -1.2 & - \\
\hline STDEV & 46 & 2.2 & & \\
\hline \hline
\end{tabular}

\section{Wake vortex predictions}

The wake vortex predictions using the average wind data of all data sources are not shown here, because the high standard deviations yield even larger uncertainties of the lateral transport than in the previous section. Employing the anemometer wind data (Figure 13) the port vortex is quite close to the A320 aircraft and lies, even under the assumption of very small uncertainties (wind direction $5^{\circ}$, wind speed $0.2 \mathrm{~m} / \mathrm{s}$, derived from the variability of the anemometer measurements within a 2 min average) within the $95 \%$ envelope. The vertical position of the port vortex and the vortex strength underpin the probability that also in this case a wake vortex encounter actually took place. 
Figure 13 Wake vortex predictions employing aircraft parameters in Table 8 and anemometer data in Table 9.
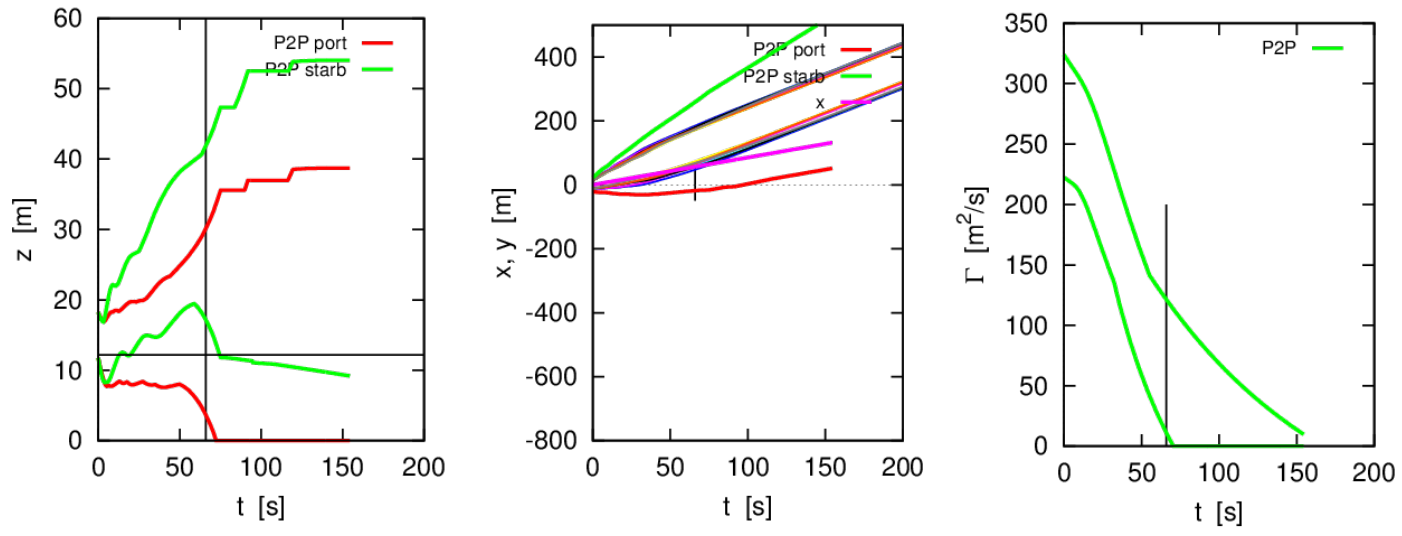

\section{Synopsis of the Incidents}

For the encounter in March 2014 and all earlier incidents (except the case in May 2013) no encounter heights are reported. For these cases with unknown flight altitudes the average height of the four incidents with a documented flight altitude amounting to $12 \mathrm{~m}$ (averaged over the whole duration of the encounter) is used. This height was selected in consultation with the local air traffic control. For these cases the wind measurements of the anemometers close to the respective runway thresholds are used, because these enabled in the well documented cases the best vortex predictions besides the aircraft measurements. Due to the limited availability of key data these incidents are of inferior interest and are not described in detail here. Table 1 provides a survey on these cases together with the conclusions drawn regarding the plausibility of a wake vortex encounter. Four cases are considered possible encounters whereas the remaining four cases, all perceived by the pilots as wind shear or turbulence, are rated as unlikely.

For the analysis of some of the incidents various sources of meteorological data have been combined comprising analysis data of the weather prediction model COSMO-DE and the weather prediction data of the ECMWF model, aircraft measurements of the leading and the encountering aircraft, as well as anemometer data and different remote sensing data from a SODAR and a wind profiler. In the investigated cases these data featured a surprisingly high spread in wind direction and strength such that the predicted probabilistic envelopes of lateral vortex transport were not conclusive to decide whether or not an encounter was likely. It was found that either the aircraft wind measurements or the data of the nearby anemometer enabled the most useful wake vortex predictions.

All cases where the pilots assumed a wake vortex encounter could actually be classified as probable or at least possible encounters. Besides there are two cases where the pilots reported wind shear but the investigations led to the conclusion that also an encounter would have been possible. It cannot be excluded that a pilot cannot perceive a weak encounter as such and would attribute the event to wind shear. At late stages decaying vortices are losing their coherent structure such that an encounter of wake vortices or turbulence can hardly be discriminated (Hennemann and Holzäpfel, 2011). So the classification as a possible wake vortex encounter appears appropriate.

Five of the eight events classified as probable or possible encounters were characterized by a meteorological situation with a tailwind in combination with weak crosswind. Because landings with tailwind are quite rare, the fraction of five out of eight events can be considered as significant. The effects of this specific wind situation on wake vortex behaviour are sketched in the following. In ground proximity a weak crosswind may compensate the vortex induced lateral transport of the luff vortex, such that the luff vortex may hover directly in the flight path of the following aircraft (Holzäpfel und Steen, 2007). Tailwind, on the other hand, transports vortex segments generated at higher flight altitudes towards the runway. At the touchdown point disturbances are generated that propagate against flight direction and weaken the vortices (Stephan et al., 2014). Additionally, the decay of the vortices is accelerated by the direct interaction of the wake vortices with the vortex sheets generated at the 
ground. This effect is the faster the lower the vortices are generated above ground. Both effects are reduced by tailwinds, because tailwinds transport less disturbed vortex segments towards the runway. In summary it can be said that in ground proximity the combination of crosswinds below $1.5 \mathrm{~m} / \mathrm{s}$ and tailwinds favours wake vortex encounters.

The installation of plate lines at the runway ends may accelerate wake vortex decay in ground proximity independent from the prevailing wind direction (Stephan et al., 2014; Holzäpfel et al., 2016a). The beneficial effects of the touchdown on vortex decay can be extended along the whole airport area where vortices may rebound to the glide slope by installing a series of plates in lines perpendicular to the flight direction. The so-called plate lines trigger the early detachment of strong $\Omega$-shaped secondary vortices that actively approach the wake vortices and subsequently propagate along the primary vortices. These dedicated secondary vortices lead to an accelerated wake vortex decay independent from the prevailing wind direction. In potentially hazardous situations caused by persistent wake vortices within the glide path, plate lines may substantially reduce vortex lifetimes and thus increase safety. This applies in particular to airports where noise abatement procedures require more frequent tailwind landings.

\section{Conclusions}

Twelve incidents attributed by the pilots either to wind shear, turbulence or wake turbulence have been investigated. Most of these incidents, occurring at a major European airport in the years 2013 to 2015, happened during final approach. Aircraft data and environmental data of different sources were applied to conduct wake vortex predictions with the Probabilistic Two-Phase Wake Vortex Decay and Transport Model (P2P) model. Whereas wind data of two numerical weather prediction models and remote sensing instrumentation at the airport featured substantial variability in wind strength and direction, anemometers located at the respective runway threshold and aircraft wind measurements yielded sufficient accuracy to assess whether a wake vortex encounter appears plausible or not.

In total, eight of the twelve investigated incidents appear plausible wake vortex encounters or are at least possible encounters, whereas 4 cases have to be excluded. All cases where the pilots assumed a wake vortex encounter could actually be classified as probable or possible encounters. This result confirms that in general pilots may recognize even weak wake vortex encounters as such and can well discriminate these encounters from wind shear and atmospheric turbulence.

In two cases flight data recorder data was available such that a very detailed analysis of the incidents could be conducted. In both cases wake vortex predictions indicate that encounters appear highly plausible. Moreover, the synopsis of wake vortex predictions, aircraft reactions, pilot inputs, and aircraft wind measurements even enabled the reconstruction of the flight tracks through the vortices. The analysis suggests that flight data recorder data including wind measurements of preferably both aircraft, the vortex generator as well as the encountering aircraft, constitute an excellent data source that may enable detailed analysis of encounters supporting clear statements whether a wake vortex was encountered or whether the induced forces and moments should rather be attributed to wind shear or turbulence.

Five of the eight events classified as probable or possible encounters were characterized by a meteorological situation consisting of a tailwind in combination with a weak crosswind. Because landings with tailwind are usually avoided and thus quite rare, this finding can be considered as significant. On one hand, in ground proximity weak crosswinds may compensate the vortex induced lateral transport of the luff vortex, such that the luff vortex may hover directly in the flight path of the following aircraft. Tailwind, on the other hand, transports disturbances generated at the touchdown point towards the runway. This way the propagation speed of the so-called end effects against flight direction is reduced such that vortex decay is delayed. It is concluded that the combination of crosswinds below $1.5 \mathrm{~m} / \mathrm{s}$ and tailwinds favours wake vortex encounters in ground proximity. As a consequence it is recommended to carefully consider such meteorological situations during any investigation intended for the readjustment of aircraft separations. 


\section{Acknowledgments}

The support of the DLR colleagues Carsten Schwarz and Dennis Vechtel of the Institute of Flight Systems with the analysis of the aircraft reaction during the encounter is greatly appreciated. Henning Dorff is gratefully acknowledged for his preliminary analysis of the encounters.

\section{References}

BADA (2013), "USER MANUAL FOR THE BASE OF AIRCRAFT DATA (BADA) REVISION 3.11", EEC Technical/Scientific Report No. 13/04/16-01, EUROCONTROL, 109 pages. http://upcommons.upc.edu/bitstream/handle/2099.1/24342/Annexl.pdf?sequence=2 (accessed 25 January 2017).

Critchley, J. and Foot, P. (1991), "UK CAA Wake Vortex Database: Analysis of Incidents Reported Between 1982 and 1990", Civil Aviation Authority, CAA Paper 91.

Crouch, J.D. and Czech, M.J. (2012), "Comparative wake wake-turbulence assessments and findings for the B747-8", 4th WakeNet3-Europe workshop, Langen, Germany, http://www.wakenet.eu/index.php?id=185 (accessed 25 January 2017).

Duffy, K., Deluca (2016), "One year of time-based separation at London's Heathrow airport", WakeNet-USA, Port Authority of NY \& NJ, New York City.

Delisi, D. P., Pruis, M.J., Wang, F.Y. and Lai, D.Y. (2013), "Estimates of the Initial Vortex Separation Distance, $b_{0}$, of Commercial Aircraft from Pulsed Lidar Data", AIAA Paper 2013-0365.

EUROCONTROL (2013), "Challenges of Growth 2013", Summary Report, http://www.eurocontrol.int/statfor (accessed 25 January 2017).

EUROCONTROL (2016), http://www.eurocontrol.int/news/recat-eu-now-use-paris-charles-de-gaulle (accessed 25 January 2017).

Frech, M. and Holzäpfel, F. (2008), "Skill of an Aircraft Wake-Vortex Model Using Weather Prediction and Observation", Journal of Aircraft, Vol. 45, No. 2, 2008, pp. 461-470, doi: 10.2514/1.28983

Gerz T., Holzäpfel F. and Darracq D. (2001), "Commercial Aircraft Wake Vortices", Progress in Aerospace Sciences, Vol. 38, No. 3, pp. 181-208.

Hallock, J.N., Greene, G.C. and Burnham, D.C. (1998), "Wake Vortex Research - A Retrospective Look", Air Traffic Control Quarterly, Vol. 6, No. 3, pp. 161-178.

Hennemann, I. and Holzäpfel, F. (2011), "Large-eddy simulation of aircraft wake vortex deformation and topology", Proc. IMechE Vol. 225 Part G: J. Aerospace Engineering, Vol. 225, pp. 1336-1350, DOI: $10.1177 / 0954410011402257$

Holzäpfel, F. (2003), "A Probabilistic Two-Phase Wake Vortex Decay and Transport Model", Journal of Aircraft, Vol. 40, No. 2, pp. 323-331.

Holzäpfel, F. and Robins, R.E. (2004), "Probabilistic Two-Phase Aircraft Wake-Vortex Model: Application and Assessment", Journal of Aircraft, Vol. 41, No. 5, pp. 1117-1126.

Holzäpfel, F. (2006), "Probabilistic Two-Phase Aircraft Wake-Vortex Model: Further Development and Assessment", Journal of Aircraft, Vol. 43, No. 3, pp. 700-708.

Holzäpfel, F. and Steen, M. (2007), "Aircraft Wake-Vortex Evolution in Ground Proximity: Analysis and Parameterization", AIAA Journal, Vol. 45, No. 1, pp. 218-227.

Holzäpfel, F., Stephan, A., Heel, T. and Körner, S. (2016a), "Enhanced Wake Vortex Decay in Ground Proximity Triggered by Plate Lines", Aircraft Engineering and Aerospace Technology, Vol. 88, Issue 2, pp. 206-214, DOI 10.1108/AEAT-02-2015-0045

Holzäpfel, F., Tchipev, N. and Stephan, A. (2016b), "Wind Impact on Single Vortices and Counterrotating Vortex Pairs in Ground Proximity", Flow, Turbulence and Combustion, Vol. 97, Issue 3, pp. 829-848, doi: 10.1007/s10494-016-9729-2. 


\section{Frank Holzäpfel}

SAFO 14007 (2014), Safety Alert for Operators, Federal Aviation Administration, available at http://www.faa.gov/other_visit/aviation_industry/airline_operators/airline_safety/safo (accessed 25 January 2017).

SESAR (2009), European Air Traffic Management Master Plan of the Single European Sky ATM Research (SESAR) project; Edition 1, SESAR Consortium.

Stephan, A., Holzäpfel, F. and Misaka, T. (2014), "Hybrid simulation of wake-vortex evolution during landing on flat terrain and with plate line", International Journal of Heat and Fluid Flow, Vol. 49, pp. 18-27, http://dx.doi.org/10.1016/j.ijheatfluidflow.2014.05.004.

WakeNet3-Europe (2015), "Aircraft Wake Vortex State-of-the-Art \& Research Needs", compiled by F. Holzäpfel et al., issued by A. Reinke, C. Schwarz, 201 pages, doi.org/10.17874/BFAEB7154B0 